\title{
Fever of unknown origin revealed to be primary splenic lymphoma: A rare case report with review of the literature
}

\author{
PAN-GE SUN, BEI CHENG, JIN-FENG WANG and PING HE \\ Department of Geriatrics, Union Hospital, Tongji Medical College, Huazhong University \\ of Science and Technology, Wuhan, Hubei 430022, P.R. China
}

Received July 23, 2016; Accepted October 13, 2016

DOI: $10.3892 / \mathrm{mco} .2016 .1110$

\begin{abstract}
Fever is a common clinical presentation of a number of diseases. A sustained unexplained fever $>38.3^{\circ} \mathrm{C}$ lasting for $>3$ weeks without an established diagnosis despite intensive diagnostic evaluation is referred to as fever of unknown origin (FUO). FUO remains a clinical challenge for physicians, as it may be attributed to a wide range of disorders, mainly infections, malignancies, non-infectious inflammatory diseases and miscellaneous diseases. We herein report the case of a 59-year-old male patient who presented with prolonged unexplained fever and was found to have a diffusely enlarged hypermetabolic spleen, as shown on ${ }^{18} \mathrm{~F}$-fluorodeoxyglucose positron emission tomography/computed tomography examination. Following splenectomy, histopathological examination revealed primary splenic lymphoma (PSL) of B-cell origin. The patient received 6 courses of systemic chemotherapy with rituximab, etoposide, cyclophosphamide, doxorubicin, vincristine and prednisone (R-ECHOP regimen) and responded well to treatment. Thus, in patients with FUO and splenomegaly, the possibility of PSL should be taken into consideration.
\end{abstract}

\section{Introduction}

The term 'fever of unknown origin' (FUO) was first introduced by Petersdorf and Beeson in 1961 based on an analysis of 100 cases, and it was defined as recurrent fever $>38.3^{\circ} \mathrm{C}$,

Correspondence to: Dr Ping He, Department of Geriatrics, Union Hospital, Tongji Medical College, Huazhong University of Science and Technology, 1277 Jie-Fang Avenue, Wuhan, Hubei 430022, P.R. China

E-mail: doctorpeace74@gmail.com

Abbreviations: FUO, fever of unknown origin; PSL, primary splenic lymphoma; FDG, fluorodeoxyglucose; PET, positron emission tomography; CT, computed tomography; NHL, non-Hodgkin lymphoma; H\&E, hematoxylin and eosin; sFNA, splenic fine-needle aspiration; $\mathrm{sCB}$, splenic core biopsy

Key words: fever of unknown origin, primary splenic lymphoma, ${ }^{18} \mathrm{~F}$-fluorodeoxyglucose-positron emission tomography/computed tomography, splenomegaly, splenectomy lasting for $>3$ weeks, remaining undiagnosed after 1 week of in-hospital evaluation (1). Several decades later, the criteria of FUO diagnosis have changed and it is currently defined by lack of a definitive diagnosis after appropriate inpatient or outpatient evaluation (2). In view of the patient's clinical circumstances and underlying immune status, FUO was categorized into classic, nosocomial, neutropenic and human immunodeffiency virus (HIV)-associated FUO by Durack and Street in 1991 (3). The etiologies of classic FUO mainly include infections, malignancies, non-infectious inflammatory diseases and miscellaneous causes, while some cases remain undiagnosed $(4,5)$.

Primary splenic lymphoma (PSL) is a rare malignant lymphoma with an incidence of $\sim 1 \%$ among patients with non-Hodgkin lymphoma (NHL) (6), although the spleen is involved in approximately half of the cases of Hodgkin's disease and one-third of NHLs as part of systemic disease $(7,8)$. Dasgupta et al (9) strictly defined PSL as lymphoma originating in the spleen and limited to the spleen and splenic hilum, without invasion of other sites, with an interval of $\geq 6$ months prior to the appearance of lymphoma elsewhere.

We herein present the case of a 59-year-old male patient with diffuse large B-cell PSL, who only exhibited sustained fever, without other remarkable complaints. To investigate the cause of the FUO, fluorine-18-fluorodeoxyglucose positron emission tomography/computed tomography $\left({ }^{18} \mathrm{~F}-\mathrm{FDG}-\mathrm{PET} / \mathrm{CT}\right)$ examination was performed and revealed a diffusely enlarged hypermetabolic spleen. Following diagnostic splenectomy, the histopathological diagnosis was diffuse large B-cell primary splenic NHL.

\section{Case report}

A 59-year-old male patient presented with a history of fever for 1 month. The temperature reached $>39^{\circ} \mathrm{C}$, with episodes of chills, and the fever subsided spontaneously several hours later, followed by sweating, which happened 1-2 times/day. A mild cough with a small amount of white foamy phlegm were the only other complaints. The patient's condition had been treated as an infectious disease, with administration of cephalosporin for 7 days and sequential quinolone for 2 days prior to hospitalization, but without improvement of the symptoms. The patient had undergone perianal abscess removal surgery 1 year prior, and denied a history of tobacco, alcohol, or illicit 
drug use. There was also no report of food or medication allergies.

On admission, the patient's temperature was $36.8^{\circ} \mathrm{C}$, with a pulse rate of 70 beats per minute. The findings of the physical examination were unremarkable, apart from bilateral moist crackles and coarse breath sounds in the lungs, dental caries and multiple folliculitis on the face and neck. On laboratory investigation, the complete blood count revealed mild anemia, with a hemoglobin level of $116 \mathrm{~g} / \mathrm{l}$. Urinalysis revealed proteinuria and occult blood, and the biochemical profile revealed mild hepatic function test abnormalities, with a total protein level of $52 \mathrm{~g} / \mathrm{l}$, an albumin level of $29 \mathrm{~g} / \mathrm{l}$ and a serum lactate dehydrogenase level of $626 \mathrm{U} / 1$. The patient had increased parameters of inflammation and infection, with an erythrocyte sedimentation rate (ESR) of $59 \mathrm{~mm} / \mathrm{h}$ (normal, $<20 \mathrm{~mm} / \mathrm{h}$ ), a high-sensitivity C-reactive protein (CRP) level of $63.7 \mathrm{mg} / 1$ (normal, $<8 \mathrm{mg} / \mathrm{l}$ ) and a procalcitonin level of $23.96 \mathrm{ng} / \mathrm{ml}$ (normal, $<0.5 \mathrm{ng} / \mathrm{l}$ ). The indicators of autoimmune disease, such as extractable nuclear antigen and antineutrophil cytoplasmic antibodies, were all negative. Screening for specific infectious diseases, including tuberculosis, malaria, enteric fever, viral infections such as HIV, cytomegalovirus, Epstein-Barr virus (EBV) and coxsackievirus, was negative. The blood, urine and stool cultures were negative. However, the sputum culture was positive for Enterobacter cloacae and Candida albicans. CT scanning of the chest revealed bilateral interstitial changes in the lung bases, with enlarged lymph nodes in the mediastinum. Abdominal ultasonography revealed splenomegaly $(13.2 \times 4.5 \mathrm{~cm})$ with normal echotexture. The findings of magnetic resonance imaging of the brain were normal.

Taken together, the results of these examinations indicated that infection occurred during the course of the disease, but the infectious factor was clearly not the only cause of the fever, as the patient's temperature would still increase to $\leq 40^{\circ} \mathrm{C}$, whether all antibiotics were stopped on admission, as the patient's vital signs were stable, or whether empirical therapy was adopted using antibiotics against gram-positive or -negative bacteria and fungi, intermittent steroids, and even diagnostic treatment with antimalarials.

To clearly determine the cause of the unexplained fever, more specialized examinations were performed. The peripheral blood and bone marrow aspiration films did not reveal any abnormalities, and the bone marrow culture was negative. However, the patient's condition did not improve and he developed dyspnea, fatigue and malaise, despite antibiotic treatment and intermittent glucocorticoid therapy. The complete blood count revealed progressive decrease of the red blood cell count, hemoglobin concentration and platelet count over 2 weeks. A ${ }^{18} \mathrm{~F}-\mathrm{FDG}-\mathrm{PET} / \mathrm{CT}$ scan was performed to investigate the possibility of a malignant neoplasm, and it revealed an enlarged spleen with diffuse increased uptake of ${ }^{18} \mathrm{~F}$-FDG, without involvement of lymph nodes or other organs (Fig. 1). Diagnostic splenectomy was performed after obtaining the patient's informed consent. The histopathological diagnosis was diffuse large B-cell primary splenic NHL with splenic hilar lymph node involvement (3/3). Immunohistochemical staining of the tumor cells was positive for CD20, CD5, multiple myeloma oncogene 1, paired box 5 and B-cell lymphoma (BCL) 2, and the Ki-67 labeling index was $>90 \%$; the cells were negative

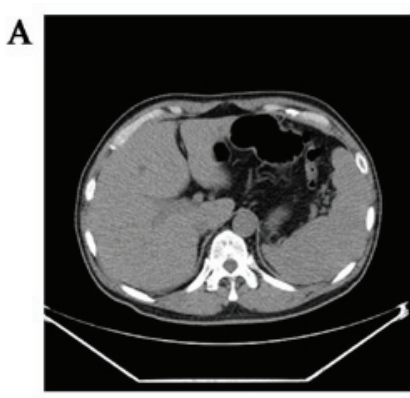

B

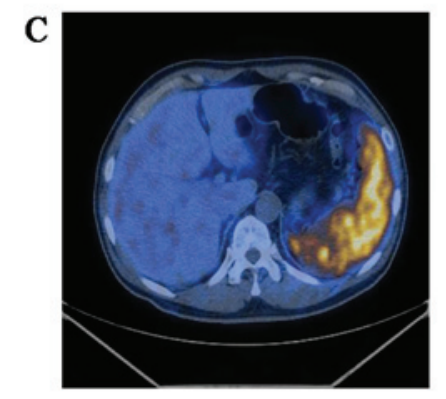

D

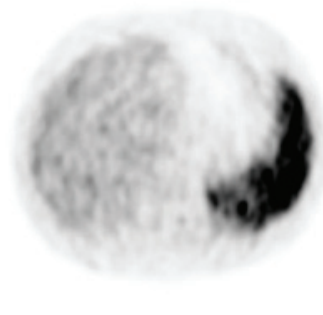

Figure 1. Whole-body ${ }^{18}$ F-FDG-PET/CT images: Transaxial views of (A) CT, (B) PET and (C) PET/CT showing an enlarged spleen with diffusely increased uptake of ${ }^{18} \mathrm{~F}$-FDG. (D) Coronal views on whole-body PET did not reveal involvement of other organs. FDG, fluorodeoxyglucose; PET, positron emission tomography; CT, computed tomography.

for CD3, CD21, CD30, CD10, BCL6 and cyclin D1 (Fig. 2). EBV-encoded RNA was negative by in situ hybridization of EBV. The patient received chemotherapy with rituximab, etoposide, cyclophosphamide, doxorubicin, vincristine and prednisone (R-ECHOP regimen) and responded well to this treatment. However, after 2 courses of chemotherapy, the patient developed fever again, with a decrease in the platelet count, hemoglobin level and granulocyte number, and abnormal hepatic function. The bone marrow aspiration revealed the presence of hemophagocytic cells. VP16, dexamethasone and $\gamma$-globulin were administered, as hemophagocytic syndrome was suspected. The patient's temperature and complete blood count returned to normal, but the liver function was not restored until $\sim 1$ month later, after which time chemotherapy was continued. A total of 6 chemotherapy cycles were administered and the patient responded well to this treatment. Until the date of the last follow-up (May 30, 2016), the patient had not developed any other discomfort.

\section{Discussion}

PSL is a rare malignant disease with an ambiguous definition, as the spleen is involved in a number of malignancies, particularly hematological malignancies, such as Hodgkin's lymphoma and NHL $(6,7,10,11)$. In addition to the splenic lesions, the strict diagnostic criteria of PSL include i) splenomegaly, ii) excluding involvement of other sites by laboratory tests and imaging studies, iii) negative liver and lymph node biopsies, and iv) disease-free status for $\geq 6$ months after splenectomy (9). PSL was grouped into three stages by Ahmann et al (10), depending on the extent of the disease: In stage I, the tumor is limited to the spleen; in stage II, the splenic hilum nodes are involved; and stage III includes involvement of the liver or lymph nodes beyond the splenic hilum; the patient in our case had stage II 
A

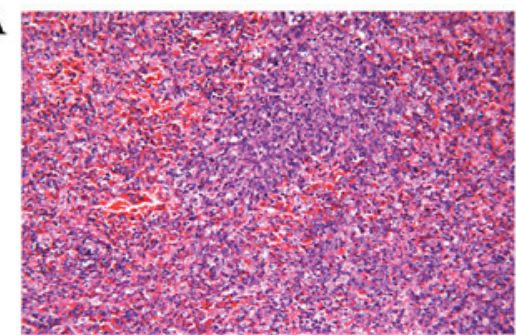

C

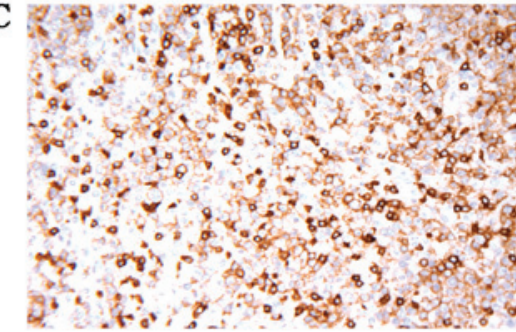

$\mathbf{E}$
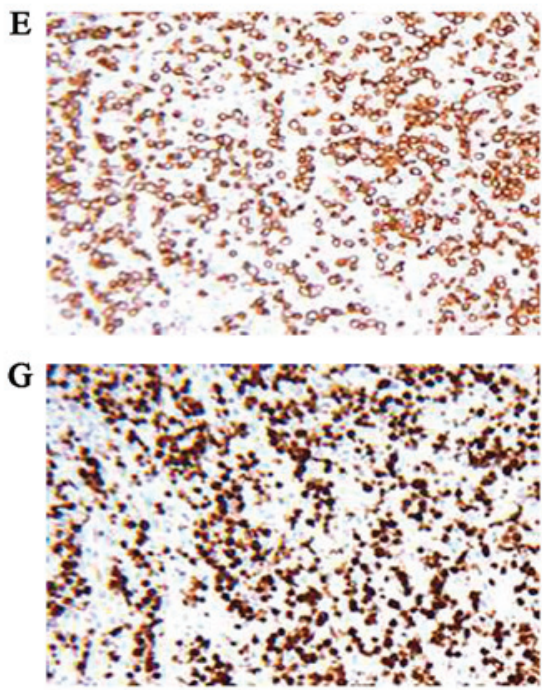

B

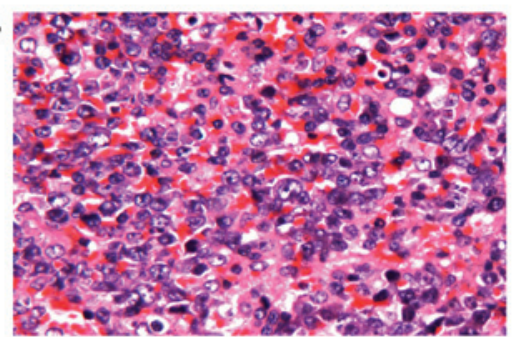

D

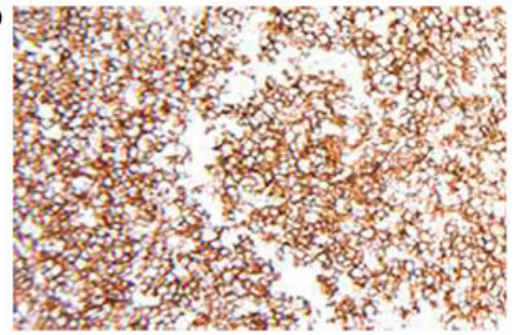

F

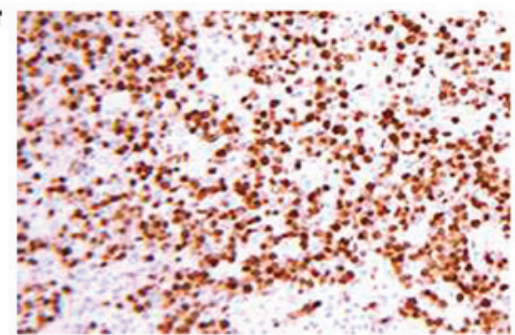

$\mathrm{H}$.

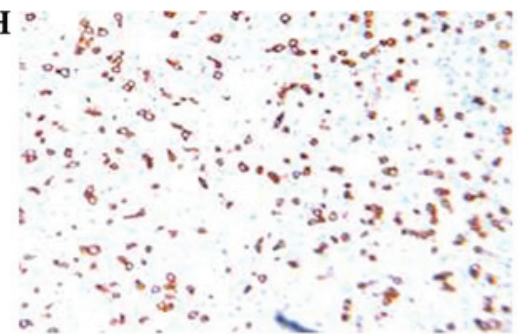

Figure 2. Histopathological examination of the spleen. (A and B) Hematoxylin and eosin (H\&E) staining; (C-H) immunohistochemical staining. (A) H\&E; magnification, x200. (B) H\&E; magnification, x400. (C) CD5; magnification, x400. (D) CD20; magnification, x400. (E) B-cell lymphoma 2; magnification, x40. (F) multiple myeloma oncogene 1; magnification, x400. (G) Ki-67, magnification, x400. (H) CD3; magnification, x400

disease. The most common histological subtype of PSLs is large B-cell type $(12,13)$. The most common presenting symptoms of PSL are fever, malaise, left upper quadrant pain, weight loss and night sweats $(14,15)$. Furthermore, during the early stages of the disease, patients tend to be asymptomatic (16) and physical examination or laboratory tests usually cannot provide specific diagnostic information, which greatly increases the difficulty of diagnosing true PSL. However, imaging studies may provide more useful information for the diagnosis.

FUO is a common manifestation of a number of diseases, which are classified into infections, malignancies, non-infectious inflammatory diseases, miscellaneous causes and undiagnosed conditions (4,5). Among these etiologies, infection was the most common cause of FUO in the 1961 survey (1). However, according to Petersdorf's study published in 1992, neoplastic disease had surpassed infectious diseases as the etiology of classic FUO (2), while in more recent studies, the percentage of neoplastic causes has decreased and that of non-infectious inflammatory diseases and undiagnosed conditions has increased (5,17-19). The changes of the etiology proportion of FUO may be attributed to diagnostic advances, particularly the improvement of imaging and microbiological studies $(4,18,19)$. Among the neoplastic causes of FUO, malignant lymphomas are the most common (20). Besides PSL, other rare sites of lymphomas manifesting as FUO, such as intravascular lymphoma (21), primary central nervous lymphoma (22), colonic lymphoma (23) and pituitary lymphoma (24), have also been reported.

FUO remains a clinical challenge for physicians, as the overall mortality from FUO is $12-35 \%$, with undiagnosed conditions accounting for $>20 \%$ in the 1990 s and 2000 s, despite the advances in diagnostic modalities (5).

In the present case, the diagnosis of lymphoma was suspected prior to splenectomy, as ${ }^{18} \mathrm{~F}-\mathrm{FDG}-\mathrm{PET} / \mathrm{CT}$ revealed an enlarged spleen with increased ${ }^{18} \mathrm{~F}-\mathrm{FDG}$ uptake. As reported in the literature, ${ }^{18} \mathrm{~F}-\mathrm{FDG}$ PET/CT may help establish the final diagnosis of FUO, as it is sensitive to the major causes of FUO, including infections, malignancies and non-infectious inflammatory diseases (25-27). Kim et al (26) retrospectively evaluated the role of ${ }^{18} \mathrm{~F}-\mathrm{FDG} \mathrm{PET} / \mathrm{CT}$ in the final diagnosis of FUO and found that it contributed to $65.8 \%$ of the cases. More significantly, for classic FUO patients with 
elevated ESR and CRP levels, ${ }^{18}$ F-FDG PET/CT has a high positive predictive value (93\%) and a high negative predictive value (100\%) (28). In addition, ${ }^{18} \mathrm{~F}-\mathrm{FDG}-\mathrm{PET} / \mathrm{CT}$ has also been reported as an important tool in the diagnosis, staging, detection of recurrence and monitoring of the treatment response in PSL cases (29-31). A retrospective study demonstrated that ${ }^{18} \mathrm{~F}-\mathrm{FDG}-\mathrm{PET} / \mathrm{CT}$ has a sensitivity of $96.2 \%$, a specificity of $91.7 \%$ and an accuracy of $94 \%$ in the diagnosis/staging and restaging of PSL (31). Other studies have reported a sensitivity of $100 \%$ and a specificity of $95-100 \%$ of ${ }^{18} \mathrm{~F}-\mathrm{FDG}-\mathrm{PET} / \mathrm{CT}$ for the detection of splenic involvement in malignant lymphoma $(32,33)$.

Splenic fine-needle aspiration (sFNA), splenic core biopsy (sCB) and splenectomy are the optimal invasive procedure for diagnosing PSL. Both sFNA and sCB are safe for patients with splenomegaly, and certain studies reported they exhibit excellent diagnostic accuracy in splenic malignancies, but a relatively low efficiency in splenic lymphoma $(34,35)$. However, other studies indicated they have a rather low diagnostic yield on account of inadequate specimenin addition, in a review of 49 cases there was an overall complication rate of $16 \%$, and complications such as bleeding and splenic rupture may have a fatal outcome $(36,37)$. In patients with diffuse malignant diseases involving the spleen, splenic puncture may increase the risk of hemorrhage or rupture (38). Thus, for patients in a poor condition or those with contraindications to splenectomy, sFNA and sCB may be feasible options.

Splenectomy is not only a diagnostic procedure, but also a therapeutic choice for splenic lymphoma $(10,39,40)$. As indicated by a retrospective study, splenectomy achieves a high diagnostic rate in patients with unexplained splenomegaly or splenic masses (12). In addition, early splenectomy may reverse cytopenias and significantly improve the prognosis for PSL or NHL patients, even at an advanced stage $(41,42)$. Furthermore, splenectomy is considered to be an effective procedure for establishing the cause of splenomegaly and FUO, similar to the present case (38).

In addition to splenectomy, treatments for PSL include systemic chemotherapy and radiotherapy; however, splenectomy may be preferable, as it provides correct diagnosis and effective treatment (16). Splenectomy followed by combination chemotherapy may achieve excellent long-term survival.

The diagnosis of PSL or the establishment of the cause of FUO may be difficult. In this rare case of PSL presenting with FUO and splenomegaly, ${ }^{18} \mathrm{~F}-\mathrm{FDG}-\mathrm{PET} / \mathrm{CT}$ and splenectomy were proven to be of great value in establishing the final diagnosis. PSL should be taken into consideration in the differential diagnosis of patients with FUO and splenomegaly.

\section{Acknowledgements}

The present study was supported by grants from the National Natural Science Foundation of China (nos. 30900599 and 81470027).

\section{References}

1. Petersdorf RG and Beeson PB: Fever of unexplained origin: report on 100 cases. Medicine (Baltimore) 40: 1-30, 1961.

2. Petersdorf RG: Fever of unknown origin. An old friend revisited. Arch Intern Med 152: 21-22, 1992
3. Durack DT and Street AC: Fever of unknown origin-reexamined and redefined. Curr Clin Top Infect Dis 11: 35-51, 1991.

4. Hayakawa K, Ramasamy B and Chandrasekar PH: Fever of unknown origin: an evidence-based review. Am J Med Sci 344: 307-316, 2012.

5. Mourad O, Palda V and Detsky AS: A comprehensive evidence-based approach to fever of unknown origin. Arch Intern Med 163: 545-551, 2003.

6. Brox A and Shustik C: Non-Hodgkin's lymphoma of the spleen. Leuk Lymphoma 11: 165-171, 1993.

7. Gobbi PG, Grignani GE, Pozzetti U, Bertoloni D, Pieresca C, Montagna G and Ascari E: Primary splenic lymphoma: Does it exist? Haematologica 79: 286-293, 1994.

8. Rueffer U, Sieber M, Stemberg M, Gossmann A, Josting A, Koch T, Grotenhermen F and Diehl V; German Hodgkin's Lymphoma Study Group (GHSG): Spleen involvement in Hodgkin's lymphoma: assessment and risk profile. Ann Hematol 82: 390-396, 2003.

9. Dasgupta T, Coombes B and Brasfield RD: Primary malignant neoplasms of the spleen. Surg Gynecol Obstet 120: 947-960, 1965.

10. Ahmann DL, Kiely JM, Harrison EG Jr and Payne WS: Malignant lymphoma of the spleen. A review of 49 cases in which the diagnosis was made at splenectomy. Cancer 19: 461-469, 1966.

11. Straus DJ, Filippa DA, Lieberman PH, Koziner B, Thaler HT and Clarkson BD: The non-Hodgkin's lymphomas. I. A retrospective clinical and pathologic analysis of 499 cases diagnosed between 1958 and 1969. Cancer 51: 101-109, 1983.

12. Kraus MD, Fleming MD and Vonderheide RH: The spleen as a diagnostic specimen: a review of 10 years' experience at two tertiary care institutions. Cancer 91: 2001-2009, 2001.

13. Shimizu-Kohno K, Kimura Y, Kiyasu J, Miyoshi H, Yoshida M, Ichikawa R, Niino D and Ohshima K: Malignant lymphoma of the spleen in Japan: a clinicopathological analysis of 115 cases. Pathol Int 62: 577-582, 2012.

14. Spier CM, Kjeldsberg CR, Eyre HJ and Behm FG: Malignant lymphoma with primary presentation in the spleen. A study of 20 patients. Arch Pathol Lab Med 109: 1076-1080, 1985.

15. Harris NL, Aisenberg AC, Meyer JE, Ellman L and Elman A: Diffuse large cell (histiocytic) lymphoma of the spleen. Clinical and pathologic characteristics of ten cases. Cancer 54: 2460-2467, 1984.

16. Han SM, Teng CL, Hwang GY, Chou G and Tsai CA: Primary splenic lymphoma associated with hemophagocytic lymphohistiocytosis complicated with splenic rupture. J Chin Med Assoc 71: 210-213, 2008.

17. Efstathiou SP, Pefanis AV, Tsiakou AG, Skeva II, Tsioulos DI, Achimastos AD and Mountokalakis TD: Fever of unknown origin: discrimination between infectious and non-infectious causes. Eur J Intern Med 21: 137-143, 2010.

18. Kaya A, Ergul N, Kaya SY, Kilic F, Yilmaz MH, Besirli K and Ozaras R: The management and the diagnosis of fever of unknown origin. Expert Rev Anti Infect Ther 11: 805-815, 2013.

19. Mete B, Vanli E, Yemisen M, Balkan II, Dagtekin H, Ozaras R, Saltoglu N, Mert A, Ozturk R and Tabak F: The role of invasive and non-invasive procedures in diagnosing fever of unknown origin. Int J Med Sci 9: 682-689, 2012.

20. Roca Campañá V and Rodríguez Silva H: Malignant lymphomas presenting as fever of unknown origin. An Med Interna 24: 531-534, 2007 (In Spanish).

21. Zeidman A, Horowitz A, Fradin Z, Cohen A, Wolfson L and Elimelech O: Fulminant intravascular lymphoma presenting as fever of unknown origin. Leuk Lymphoma 45: 1691-1693, 2004.

22. Salih SB, Saeed AB, Alzahrani M, Al QM, Haider A and Palker V: Primary CNS lymphoma presenting as fever of unknown origin. J Neurooncol 93: 401-404, 2009.

23. Casallo Blanco S, de Matías Salces L, Marcos Sánchez F, Martín Barranco MJ, Núñez Cuerda E and Solano Ramos F: Colon lymphoma as a cause of fever of unknown origin. An Med Interna 23: 379-381, 2006.

24. Landman RE, Wardlaw SL, McConnell RJ, Khandji AG, Bruce JN and Freda PU: Pituitary lymphoma presenting as fever of unknown origin. J Clin Endocrinol Metab 86: 1470-1476, 2001.

25. Meller J, Sahlmann CO and Scheel AK: ${ }^{18}$ F-FDG PET and PET/CT in fever of unknown origin. J Nucl Med 48: 35-45, 2007.

26. Kim YJ, Kim SI, Hong KW and Kang MW: Diagnostic value of ${ }^{18} \mathrm{~F}$-FDG PET/CT in patients with fever of unknown origin. Intern Med J 42: 834-837, 2012.

27. Qiu L and Chen Y: The role of ${ }^{18} \mathrm{~F}$-FDG PET or PET/CT in the detection of fever of unknown origin. Eur J Radiol 81: 3524-3529, 2012. 
28. Balink H, Collins J, Bruyn GA and Gemmel F: F-18 FDG $\mathrm{PET} / \mathrm{CT}$ in the diagnosis of fever of unknown origin. Clin Nucl Med 34: 862-868, 2009.

29. Karunanithi S, Roy SG, Murugan V, Bal C and Kumar R: ${ }^{18} \mathrm{~F}-\mathrm{FDG}-\mathrm{PET} / \mathrm{CT}$ in staging, recurrence detection and response evaluation of primary splenic lymphoma with eight years follow up. Nucl Med Rev Cent East Eur 18: 37-38, 2015.

30. Takata F, Kaida H, Ishibashi M, Kurata S, Uozumi J, Uchida M, Okamura T, Uchida S, Oshima K, Ban S, et al: Primary splenic lymphoma detected by F-18 FDG PET. Clin Nucl Med 33 204-207, 2008

31. Karunanithi S, Sharma P, Roy SG, Vettiyil B, Sharma A, Thulkar S, Bal C and Kumar R: Use of ${ }^{18} \mathrm{~F}-\mathrm{FDG}$ PET/CT imaging for evaluation of patients with primary splenic lymphoma. Clin Nucl Med 39: 772-776, 2014.

32. Rini JN, Leonidas JC, Tomas MB and Palestro CJ: ${ }^{18} \mathrm{~F}-\mathrm{FDG}$ PET versus CT for evaluating the spleen during initial staging of lymphoma. J Nucl Med 44: 1072-1074, 2003.

33. de Jong PA, van Ufford HM, Baarslag HJ, de Haas MJ, Wittebol SH, Quekel LG and de Klerk JM: CT and ${ }^{18}$ F-FDG PET for noninvasive detection of splenic involvement in patients with malignant lymphoma. AJR Am J Roentgenol 192: 745-753, 2009

34. Tam A, Krishnamurthy S, Pillsbury EP, Ensor JE, Gupta S, Murthy R, Ahrar K, Wallace MJ, Hicks ME and Madoff DC: Percutaneous image-guided splenic biopsy in the oncology patient: an audit of 156 consecutive cases. J Vasc Interv Radiol 19: 80-87, 2008.

35. Civardi G, Vallisa D, Berté R, Giorgio A, Filice C, Caremani M, Caturelli E, Pompili M, De Sio I, Buscarini E and Cavanna L: Ultrasound-guided fine needle biopsy of the spleen: high clinical efficacy and low risk in a multicenter Italian study. Am J Hematol 67: 93-99, 2001.
36. Lishner M, Lang R, Hamlet Y, Halph E, Steiner Z, Radnay J and Ravid M: Fine needle aspiration biopsy in patients with diffusely enlarged spleens. Acta Cytol 40: 196-198, 1996.

37. Lal A, Ariga R, Gattuso P, Nemcek AA and Nayar R: Splenic fine needle aspiration and core biopsy. A review of 49 cases. Acta Cytol 47: 951-959, 2003.

38. Han B, Yang Z, Yang T, Gao W, Sang X, Zhao Y and Shen T: Diagnostic splenectomy in patients with fever of unknown origin and splenomegaly. Acta Haematol 119: 83-88, 2008.

39. Grosskreutz C, Troy K and Cuttner J: Primary splenic lymphoma: Report of 10 cases using the Real classification. Cancer Invest 20: 749-753, 2002.

40. Kehoe J and Straus DJ: Primary lymphoma of the spleen. Clinical features and outcome after splenectomy. Cancer 62: 1433-1438, 1988.

41. Morel P, Dupriez B, Gosselin B, Fenaux P, Estienne MH, Facon T, Jouet JP and Bauters F: Role of early splenectomy in malignant lymphomas with prominent splenic involvement (primary lymphomas of the spleen). A study of 59 cases. Cancer 71: 207-215, 1993.

42. Lehne G, Hannisdal E, Langholm R and Nome O: A 10-year experience with splenectomy in patients with malignant non-Hodgkin's lymphoma at the norwegian radium hospital. Cancer 74: 933-939, 1994. 